\title{
Analysis of the Factors Influencing the Development of China's Financial and Economic Development
}

\author{
Chen Andong \\ Faculty of Economics and Law, Zhejiang University of Commerce and Industry Hangzhou Business School, Hangzhou, China
}

\section{Emial address:}

215863747@qq.com

\section{To cite this article:}

Chen Andong. Analysis of the Factors Influencing the Development of China's Financial and Economic Development. Science Innovation. Vol. 6, No. 4, 2018, pp. 214-219. doi: 10.11648/j.si.20180604.17

Received: June 22, 2018; Accepted: July 12, 2018; Published: July 20, 2018

\begin{abstract}
Judging from the current situation of economic development, financial and economic development and innovation are currently the most important development content, because it is already the most significant feature of modern economic development, coupled with the current rising level of scientific and technological development, so in such conditions Below, the development model of the financial economy has taken a new path. However, more and more factors are currently affecting the development of the financial economy, which makes China's level of development in this area subject to certain restrictions, so should strengthen further research on it. This requires that the entire financial sector must change its development thinking and innovate in development. This article will focus on analyzing the main factors affecting the development of the financial economy, and then propose certain solutions.
\end{abstract}

Keywords: Financial Economy, Development and Innovation, Influencing Factors

\section{浅析影响我国金融经济发展创新的因素}

\section{陈安东}

经法分院, 浙江工商大学杭州商学院, 杭州, 中国

\section{邮箱}

215863747@qq.com

摘要：从目前经济发展的状况来看, 金融经济发展和创新是当下最为重要的内容, 因为它已经成为现代经济发展最为 显著的特征, 再加上现在科技发展水平日益上升, 所以在这样的大环境下，金融经济的发展模式已经进入了创新阶段。 但是目前影响金融经济发展的因素越来越多, 使得中国在该方面的发展水平受到一定的限制, 所以应该对其加强进一 步的研究。这就需要整个金融领域必须转变发展思想, 对发展进行创新。本文将着重分析影响金融经济发展主要因素, 然后提出一定的解决措施。

关键词：金融经济，发展创新，影响因素

\section{1. 引言}

科学技术的发展带动了金融经济的发展, 目前科学技 术在金融领域的使用已经相当广泛，科学技术的使用使得
金融经济逐渐向资本金融方向转变, 并且发展为产业金融, 这样给经济的发展起到了基本的推动作用。在二十世纪的 
七十年代, 西方国家进入金融创新阶段。新的技术、工具 和与之配套的系统已经形成, 在全球化发展趋势越来越明 显的背景下, 每个国家都开始进行相应的变革, 以实际行 动参与其中, 一举获益。中国也不例外, 建立好市场环境 是其社会不断发展的前提, 因为中国本身是社会主义制 度, 因此与西方不同, 有必要在很多方面作出相应的调 整, 以尽量减少发展的阻力因素。实际上, 影响金融创 新的因素很多, 限制条件也需要一一进行突破。长期以 来, 中国的产业水平处于一个固定的水平, 要实现突破, 就必须提出更加有效的变革策略, 为经济发展作出财政 方面的贡献。从1969年Goldsmith提出金融结构理论以来, 许多学者对各国的金融结构进行了大量研究。由于经济 体制以及所处的经济发展环境不同，不同国家之间形成 了不同类型的金融结构。目前，中国正处于对金融结构 进行变革的重要时期, 金融结构是影响经济结构的重要 因素, 也是影响经济增长的关键因素, 对其进行研究有 着比较明显的实际意义。吴晓 (2016) 认为影响城市化 发展的因素很多, 金融发展和技术创新是解决这一问题 的两个重要因素。前者为城市化建设提供了资金支持, 后者为其后期转型提供了新的高科技保障, 双方在城市 化进程中相互补充[1]。有学者从新型金融模式入手进行 分析, 何学龙 (2016) 基于互联网经济学的经济理论以 及相关的长尾理论, 运用实证方法分析影响其不断发展 的主要因素, 由此试图建立影响因素的定量分析和验证 模型[2]。郭笑言 (2017) 突出金融家的作用, 认为在整 个社会经济结构中, 金融经济是一个重要组成部分, 在 整体经济发展中占有重要地位。因此, 在社会发展的新 形势下, 金融家应该在发展过程中进行创新, 以确保能 够取得更好的发展成果[3]。周飞（2017）将目光放在金 融集聚上, 认为通过这一途径不仅会促进技术创新的实 现，还会对服务创新效应，人力资本效应，产业集聚效 应和信息传播效应产生或多或少的影响 [4]。万竹青(2017) 提到有必要认识整个金融领域金融和经济发展的特点和 目标, 彻底改变观念, 大胆从制度建设, 技术创新和开 放市场中实现金融和经济的创新发展, 提高自身的竞争 能力 [5]。目前金融产品使得金融市场更加丰富, 以此使 得金融市场更加开放，促进了其国际化发展，但是正是 因为金融市场的野蛮式扩张使得金融经济的风险进一步 提升, 所以说金融经济的发展的任务任重道远。因此, 本文所进行的研究工作对于破解金融创新难题有一定的 参考价值。

\section{2. 发展现状}

\section{1. 结构存在问题}

在考虑到社会形态问题，建立起自身独有的经济体制 之后, 中国经济获得了比较良好的发展机遇。几十年来, 所取得的经济成绩让全世界为之震惊, 在经济方面所拥有
的“中国速度”也让经济学家们大呼不解。由于在长时间的 经济发展过程中过于注重数量的增长, 忽略了规范化管理 的问题, 因此中国的金融行业在结构上存在诸多的潜在问 题。长此以往会风险倍增, 不仅在其未来发展过程中埋下 了隐患, 也不利于当前的转型需要。中国金融行业的规模 扩张没有坚实的基础, 制度并不适用于本国实际情况, 弊 端也逐渐暴露出来。许多投资者不愿意将手上的资本投入 进来, 也是考虑到了结构不稳定的原因。由于经济结构还 不够稳定，在投资过程中可能会导致不必要的损失，所以 投资者采取观望态度, 这对中国经济的进一步发展而言是 非常不利的。同时, 缺乏重要资源也在很大程度上制约了 金融经济的发展, 使得中国在国际早期市场缺乏竞争力, 外部环境一旦发生变化, 中国的金融经济状况就会受到影 响。总的来说, 由于这些年来中国金融经济发展速度很快, 但是管理体制等方面并没有进行及时的建立和完善, 所以 目前在发展过程中存在很多问题, 其中最主要的问题就是 发展的力量过于薄弱, 风险程度较高。正是这些问题的叠 加导致目前金融经济的结构出现了问题，使企业在金融投 资方面受到限制, 从而引起中国金融经济的发展速度减缓, 在国际上也处于不利地位。

\section{2. 管理体制存在问题}

因为全球经济一体化的发展以及科学技术的不断创 新和发展, 导致目前中国传统的金融经济体制缺乏约束 力。而目前金融经济的发展主要是依靠信息技术进行管 控, 所以在操作上更加便捷, 更多的依靠网络进行运行, 因此便形成了一种比较新型的发展模式, 所以传统的管 理体制已经不能很好的适应当下的发展模式[6]。不可否 认的是, 科学技术的发展为金融经济带来了新的活力, 使其可以向着信息化的方向发展, 改变了传统的管理方 法。与此同时, 另一个较为突出的问题也需要解决: 传 统的管理体系在当下已经很难满足金融经济发展的需要。 传统管理体系虽然有着操作比较方便的优点, 可以满足 不同人群的需求, 但由于自身特点会产生强大的垄断特 性, 由此给实际工作带来了诸多困扰。因此, 对目前的 形势进行正确判断可以更好地革新现行管理体系, 使其 更好地为金融经济服务。金融市场可谓是将全世界联系 到一起, 但也正是因为这样, 所以管理体制更加复杂宂 余, 需要借助先进理念以及相关技术手段进行革新。如 果不能得到一个具体可行的解决方案, 中国的金融经济 将失去自身优势, 极有可能在国际竞争中被迫处于被动 地位, 这对未来的发展是非常不利的。通过图1可以看到, 中国的财政收入在 2015 年之后波动较大, 其波动原因与 中国金融结构的变化创新有着较为密切的关系, 金融创 新对于整体经济实力的提升有着特殊意义。另外目前金 融经济的发展不再是只对中国, 而是将其发展市场拓宽 到全球，所以金融风险也就会日益增大，所以原本的管 理体制已经不能够再对如今的金融经济进行管制。 


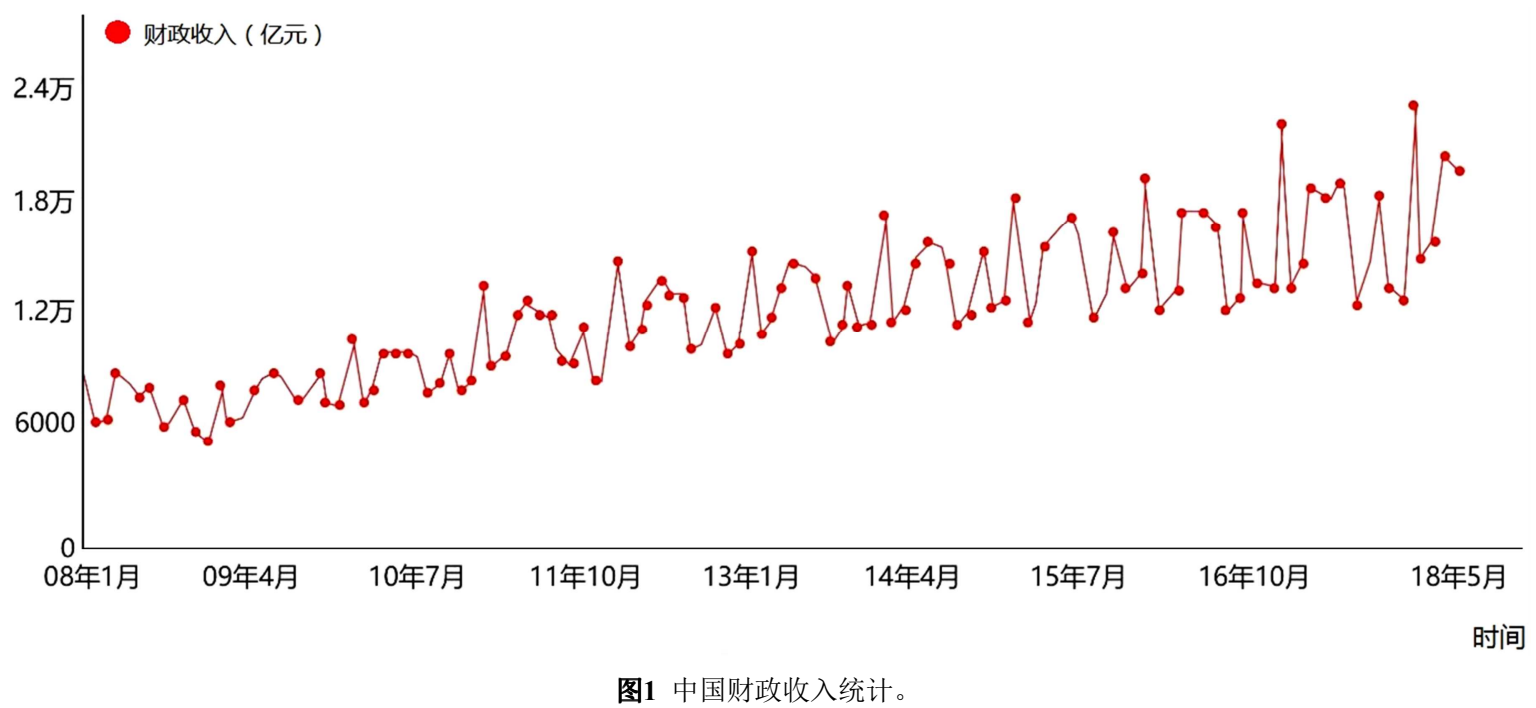

\section{3. 技术落后}

要想加快金融经济的发展进程, 首先是要进行信息的 快速传播和处理，所以信息传播速度和处理速度对金融经 济交易的便捷程度以及服务质量影响很大[7], 可以说信息 的快速准确传输直接决定了最终结果的质量。与传统的传 递方式相比, 利用网络来传递信息传输速度更快, 传递过 程中的效率非常高。计算机技术的发展不仅对社会生活的 各个方面产生了重要影响, 同时也对金融市场的操作方式 带来了新的思路, 使其可以从机械化的手动操作模式中解 放出来并逐渐转入自动化模式。信息技术为其发展提供了 全面支撑，但是，相比之下中国的金融行业所用的大部分 技术仍然滞后, 不能适应当前实际发展的需要, 严重限制 了相关行业在未来的进一步发展。对于金融经济而言, 对 信息需求的准确性要求超越了其他行业, 并且一些技术革 新是必须完成的, 否则无法在国际竞争的过程中取得优势。 但是，中国的计算机技术应用于金融经济并没有得到很好 的理解，技术的进步只能停留在表面，没有起到太多的实 际作用，技术的潜在价值没有被激发出来，这将影响中国 金融市场在未来的进一步发展。

由于计算机技术的发展以及先进的通讯设备的使用 使得金融信息的传播速度加快，并且信息传播的规模不断 扩大, 另外信息处理的效率也得到提升, 最终这一发展模 式将会越来越趋于全自动化, 所以可以看出来科学技术是 决定金融经济发展的重要因素。但是与其他发达国家相比, 中国的金融经济技术还比较落后。应用于金融经济领域的 技术创造成果寒胗无几，科技成分、速度操作和技术加工 还达不到最大的发展中国家该有的水平，对新技术产品的 认识不够全面及时, 也不能巧妙掌握。在很大程度上原本 可以得到进一步发展和提升的新金融产品受到技术限制, 不得不减少金融交易的方式, 运营速度较慢, 大大降低了 金融服务质量, 限制了金融市场发展的活力。

\section{4. 人员素质缺乏}

目前部分从业人员的专业素质已经不能够满足当今 金融经济快速发展的需求, 虽然对于金融基础知识的了解
足够透彻, 但是对于创新能力和市场的动产能力的把控还 比较欠缺, 另外对市场营销能力的理解也存在不足 [8]。除 此之外中国该行业的发展起步相对来说比较晚, 并且在经 验上欠缺, 只能是相关的理论知识进行探索, 缺乏基本的 实践性，所以在后期的创新上就显得动力不足; 另外虽然 从国外一些比较典型的事例吸取了部分经验, 但仅仅是流 于表面, 对细节的把控不足, 所以很难打开金融创新的局 面, 再加上金融人才素质偏低, 很难在创新上取得一定成 果。

\section{3. 影响因素}

\section{1. 思想认识不到位}

在中国金融经济总体是由政府主导的, 基本上属于计 划型经济[9]。虽然这种做法有一定的优势, 但是存在的弊 端却是很致命的。一般在这样的管理模式下，一些企业会 依照计划进行发展, 所以在创新上基本上比较僵化, 很难 对创新进行理解和感悟; 另外在对具体政策进行传达上存 在信息不对称，因为层级过多导致最终传达到下级时已经 对决策产生了误解, 并且很多企业很难发现自身存在的问 题, 也无法及时进行更改, 所以在具体的执行过程中难免 会产生一定的偏差, 影响整个金融经济的发展和创新。这 样的模式持续时间越长很容易变得故步自封, 对先进的技 术也不采用, 最终将会导致创新受阻。

\section{2. 制度发展不建全}

金融制度的建立对金融经济的发展存在着深远的影 响, 但目前制度不够健全, 具体表现在中国的国有控股银 行在市场上占有很大份额, 所以在进行贷款和证券等业务 时会有国家作为基本保障, 更容易发展, 但是商业银行却 缺乏保障, 所以商业银行在业务发展上相对比较缓慢。而 对于发达国家而言, 其商业银行数量庞大, 金融业务也非 常广泛，所以金融创新能力很强。针对这样的情况政府应 该对一些管制进行开放, 对商业银行加强保护, 鼓励商业 银行的创新发展 [10]。另外世界性的金融波动也会导致金 
融行业创新和发展受到一定限制, 所以要能够尽量规避风 险, 制定出相应的备用计划, 并及时对计划进行调整, 以 备不时之需。

\section{3. 技术落后}

引进先进的科学技术并应用于金融经济的发展能够 缩减业务处理时间, 也能够降低成本费用, 使整体的业务 办理效率更加高效, 所以可以在技术的应用方面进行创新, 例如: 科学技术与金融行业之间的融合，对信息传递过程 的高效处理以及信息处理之后的保密等方面的应用创新 [11]，除此之外金融机构之间应该进行合理的资源共享， 使部分信息可以整合, 最终在进行业务处理的时候更加高 效。

\section{4. 金融风险比较大}

金融创新会对外部环境产生一定的影响, 同时带来更 多的发展机遇。但在金融经济领域, 如果只看到直接的好 处, 往往会忽略潜在的风险。主要原因是对该领域的理解 不够深入, 没有考虑风险补偿的能力。在进行金融经济发 展和创新的时风险是不可避免的, 风险的产生一方面能够 获取丰厚的利润, 另一方面也会造成成本不保。而准确预 测未来风险是非常困难的, 同时也没有办法对风险形成有 效的约束, 因此增加了金融经济市场的不确定性, 这也会 使得整个市场更加不稳定，因此如何在控制风险的前提下 对金融经济进行创新是目前应该解决的问题。

\section{4. 发展策略 \\ 4.1. 完善金融经济体制}

对于整个行业来说要想要进行稳定健康的发展就应 该建立一套科学的金融机制, 首先应该设立相应的法律条 例, 对金融实现有效控制, 保证金融行业的稳定发展 [12]; 其次再根据法律条例结合具体的情况完善现有的金融机 制, 使整体金融经济的发展能够稳定运行, 并且改变行业 内部混乱的情况, 减少一些金融机构出现的违规操作。另 外在制度的建设上要从中国发展的具体情况出发, 适当引 进发达国家先进的制度理念，但不能够生搬硬套，而应该 去粗取精, 根据自身情况进行合理转化, 以保证能够有效 促进中国金融经济的发展和创新 [13]。

例如：图2统计的是中国在2014年及2015年直接融资 分项指数情况, 为了实现中国金融经济体制的最优化改革, 可以考虑对现有结构进行适当调整, 直接融资比例应该不 断提高, 在原有资本市场体系基础上, 增加该方面所占据 的比例, 从根本上将投机市场转化为投资市场。另外, 要 继续加强债券融资比例, 大力发展企业债券市场, 根据企 业的经营状况和信贷条件, 进一步完善公司债券市场管理 机制, 以提高公司债券的流动性和实现经济增长。另外, 在中国现有的经济体系中, 国有经济比重较大, 形成了一 定的垄断局面。只有实现非国有和非银行金融机构的协调 发展, 形成合理的金融经济发展体制, 才能深化中国在该 领域的不断变革[14]。

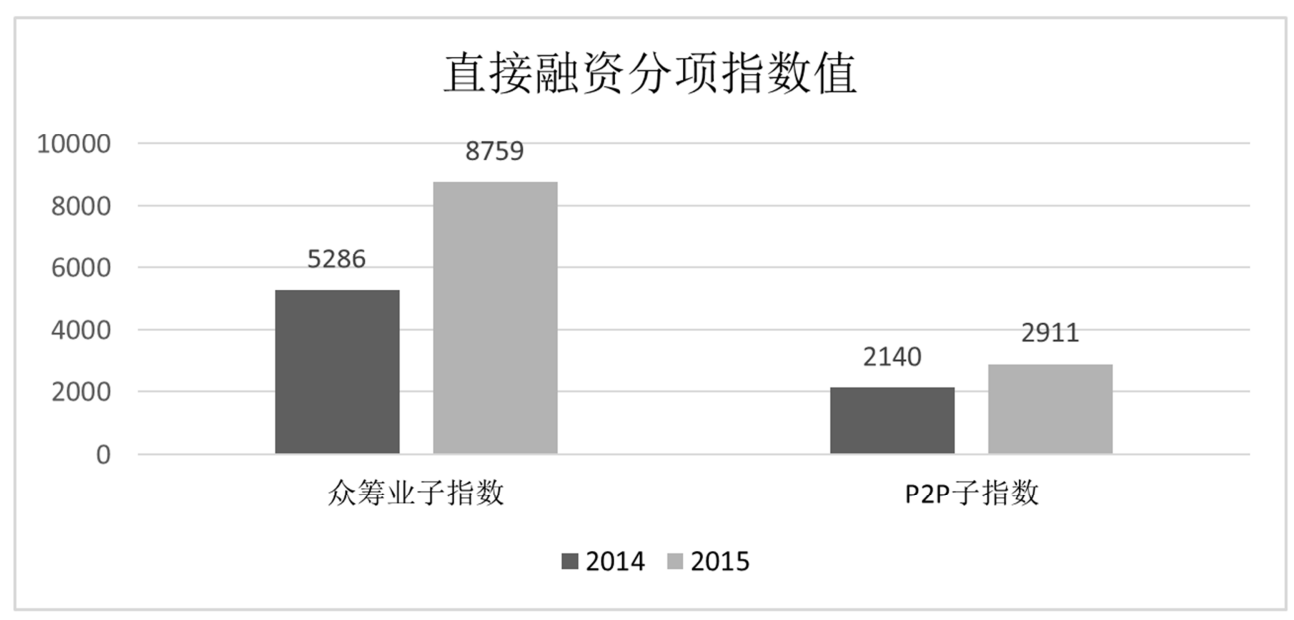

图2 直接融资分项指数情况统计。

\section{2. 培养创新精神}

在当今社会, 创新已经是各个行业前进的动力, 金融 行业的发展也不例外。从图3的统计数据中不难发现, P2P 金融、金融大数据、互联网金融消费等金融科技创新领域 的融资形势较好, 科技创新给金融领域注入了新的增长活 力, 获得了投资者的青睐。一旦拥有创新精神就等于是掌 握了发展的主命脉, 因此相关从业人员创新精神的提升对 于日后该行业的发展起着关键作用。具体来说应该先掌握
科学技术, 其次将科学技术和发展创新结合在一起, 并且 能够深挖其中存在的原理; 最后就是提升相关从业人员的 专业素质, 及时了解目前行业发展的情况, 金融机构应该 定期对员工进行培训, 使其能够了解并掌握全球金融业的 发展形势以及未来的变化趋势, 另外还可以将一些员工外 派到发达国家进行交流学习, 提高其基本的创新意识, 对 金融经济的发展和创新做出一份贡献 [15]。 


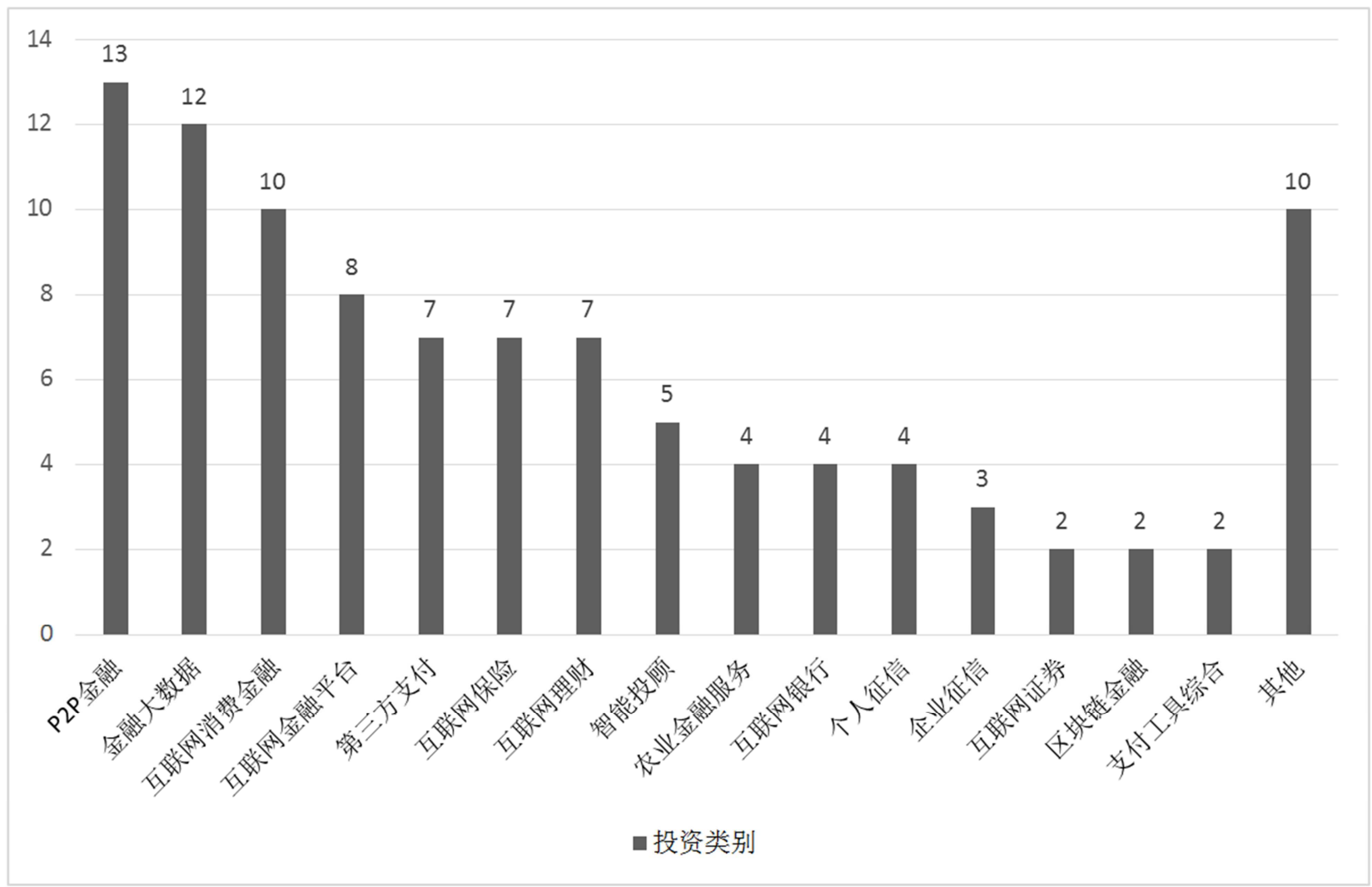

图3 2017-2018年金融科技创新获得融资的主要领域。

\section{3. 加强技术研究}

要想进行金融创新首先必须有强大的技术作为支撑, 这样可以使整个金融产业朝着多元化的方向进行发展, 能 够保证金融产业的基本结构是协调的, 并且更加具有合理 性。这样就必须要求国家注重技术人才的培养, 不能够只 注重基本理论的培养, 更加要重视实践操作, 从而在实际 工作中发挥出一定的作用; 另外在进行技术研究时必须要 重视团队的力量, 成员之间进行相互交流和沟通, 出现难 以解决的问题时整个团队要一起协商, 合力解决, 这样团 队之间进行合作迸发出来的智慧更加强大，也可以激发出 新的灵感, 这正好符合金融市场的创新需求, 长此以往, 才能够促进金融市场的创新发展。

\section{5. 结论}

在金融经济的发展中创新是主要的推动力量, 该行业 对于中国的发展来说具有很重要的意义, 但是在实际发展 中仍然是会受到一些因素的影响, 所以要能够运用有效的 方法对其进行解决, 最主要的就是要先从技术、制度方面 出发, 找出其中存在的问题, 并改善问题, 以保证金融经 济创新发展。

\section{参考文献}

[1] 吴晓.金融发展、技术创新与城市化[D].安徽财经大学,2016。
[2]何学龙.中国互联网金融创新发展的影响因素研究[D].西南 财经大学,2016。

[3] 郭笑言.金融经济发展创新的影响因素[J].环球市场信息导 报,2017(44):14-14。

[4] 周飞.开放经济下金融集聚对技术创新的影响[J].全国流通 经济,2017(24):71-72。

[5] 万竹青.影响我国金融经济发展创新的因素 [J]. 今日财 富,2017(11):169-169。

[6] 夏志华.我国金融创新的影响因素分析 [J].技术经济与管理 研究,2005(1):127-127。

[7] 胡婷雅.解读影响我国金融经济发展创新的因素[J].低碳世 界,2017(22):248-249。

[8] 齐薇.影响我国金融经济发展创新的因素分析[J].环渤海经 济瞭望,2017(10):7-7。

[9] 白云凤,宋玉杰,张鹏程.浅析影响我国金融经济发展创新的 因素[J].内蒙古煤炭经济,2017(1):32-32。

[10] 罗钦扬.影响我国金融经济发展创新的因素[J]. 今日财富(中 国知识产权),2017(12)。

[11] 顾碧波.浅析我国政府金融投资监管制度改革与创新 [J].投 资与合作:学术版,2014(12):44-45。

[12] 王永锋.新形势下中国金融监管体制改革与创新的国际经 验借鉴[J].大众投资指南,2017(9)。 
[13] 张璇,代玉红.开放条件下中国金融监管制度的创新与完善 --基于全球金融危机的重新审视 [J].河北经贸大学学 报,2014(6):95-98。

[14] 贺任飞.我国经济增长的金融因素分析 [J]. 时代金 融,2016(8):18-19。
[15] 郭富平.影响我国金融创新的因素分析与对策[J].中国科技 纵横,2013(13):241-241。 